\title{
Mediastinal Liposarcoma
}

National Cancer Institute

\section{Source}

National Cancer Institute. Mediastinal Liposarcoma. NCI Thesaurus. Code C6614.

A malignant adipose tissue neoplasm of the anterior, middle or posterior mediastinum. 